\title{
Yargıya yansıyan total diz protezi uygulamalarında tıbbi ve hukuki değerlendirme
}

\section{Medicolegal evaluation for total knee prosthesis related cases which are sued}

\author{
IIhan Açıkgöz', İrfan Esenkaya ${ }^{2 *}$, Serdar Şirazi ${ }^{3}$ \\ 1 İstanbul Barosu Avukatı, Ortopedi ve Travmatoloji Uzmanı, Hastane ve Sağlık İşletmeleri Yöneticisi, \\ Hukuk Doktoru, Sağlık Hukuku Uzmanı. Özkaş Açıkgöz Hukuk Bürosu, İstanbul \\ ${ }^{2}$ Emekli Öğretim Üyesi, SANTE Tıp Merkezi Ortopedi ve Travmatoloji Bölümü, Kadıköy, İstanbul \\ *Tıp Hukuku Yüksek Lisansı, MA \\ ${ }^{3}$ Ortopedi ve Travmatoloji Uzmanı, Hukukçu, Arabulucu. Özel Avcılar Anadolu Hastanesi; Şahin Avukatlık Bürosu, İstanbul
}

TOTBID Dergisi Total Diz Protezi sayısının bu bölümü, diz hastalıkları ve tedavileri ile ilgili olarak yaşanan uyuşmazlıklarla ilgili örnek olgular içermekte olup, olgular, meslektaşlarımıza katkı sağlamak üzere medikolegal açıdan değerlendirilmiştir. Unutulmamalıdır ki, sağlık hukuku gibi özel bir alanı anlamanın yolu, hukuk ile ilgili genel bilgileri bilmekten geçmektedir. Temel hukuk alt yapısı olmayan meslektaşlarımızla bir üst ihtisas konusu olan sağlık hukukunu tartışmak yarar sağlamayacağı gibi, alınan bilgilerin meslektaşlarımız tarafından hatalı yorumlanması ve hatalı şekillerde içselleştirilmesine sebep olacaktır. Bu sebeplerle, bu sayıda örnekler üzerinde yapılan tartışmaların, temel hukuk bilgisini içeren TOTBiD Dergisi 2020/1 sayısının içeriğine ilave olarak yapılmış tartışmalar olarak algılanması yararlı olacaktır. Örnek olgular sadeleştirilerek, özü ile sunulmuş, her olgu tek tek tahlil edilmeksizin tüme yönelik olarak ve çıkarımlara hizmet edecek bir analiz yapılmış, "tartışma" başlığı altında ayrı bir bölüm halinde tartışılmıştır.

Anahtar sözcükler: total diz protezi; malpraktis; hekimin sorumluluğu; bilirkişi raporu; sağlık hukuku

\section{ÖRNEK OLGU 1}

Elli iki yaşındaki kadın hastaya, ortopedi ve travmatoloji uzmanı olan hekim tarafindan Eylül 2012'de sağ diz protezi uygulanmış ve dört gün sonra fizik tedavi önerisi ile taburcu edilmiş. Kontrole geldiğinde "fizik tedavi sırasında sıcak uygulama yapıldığı” bilgisini veren hasta, ortopedi ve travmatoloji uzmanının sert üslubu ve "henüz tam iyileşmemiş yaralarda sıcak uygulamanın bazı bakterilerin üremesine neden olacağı” ifadesi ile karşılaşmış ve bir daha da kontrole gitmemiş. ${ }^{[1]}$
This part of the TOTBID Journal Total Knee Arthroplasty Issue includes sample cases regarding disputes related to knee diseases and their treatments, and the cases have been evaluated from a medicolegal perspective to contribute to comprehension of our colleagues. It should not noted that the way to understand a special field, such as health law, requires general information about law. Discussing health law, a higher specialization subject, with our colleagues, who do not have a basic legal background, will not be beneficial, and it will cause the information to be misinterpreted and internalized in a wrong way. In this respect, it would be beneficial to perceive the discussions regarding the sample cases in this issue as an annex to the content of the TOTBID Journal 2020/1 issue, which includes basic legal knowledge. The case studies were simplified and presented with their essence, without analyzing each case individually, and an analysis was made for the whole and to serve the inferences, and discussed in a separate section under the title of "discussion".

Keywords: total knee replacement; malpractice; the responsibility of the physician; expert report; health law

İletişim / Contact: Dr. Av. İlhan Açıkgöz • E-posta / E-mail: drilhanacikgoz@gmail.com

ORCID iD: Illhan Açıkgöz, 0000-0002-5511-0341 • İrfan Esenkaya, 0000-0002-7321-0012 • Serdar Şirazi, 0000-0002-2155-1894 
Dosya Adli Tıp Kurumuna gönderilmiş ve 2. İhtisas Kurulunca tanzim edilen Aralık 2014 tarihli raporda özetle; "ameliyat bölgesindeki enfeksiyonun ameliyattan yaklaşık olarak dört ay sonra ortaya çıktığının anlaşıldığı, ameliyat bölgesinde eklem içinde üreyen metisiline dirençli koagülaz negatif stafilokokusun, ameliyat esnasında veya taburculuktan önceki dönemde bulaşması halinde akut dönemde ameliyatı takip eden günlerde belirti vermesinin beklendiği, bu nedenle ortaya çıkan klinik tabloya göre söz konusu bakterinin şüphelilerden Dr. . . . tarafindan yapılan ameliyatta bulaşmış olmasının mümkün olmadı̆̆ı, dolayısıyla ilgili hekim ve hastane personeli olan şüphelilere atfı kabil bir kusurun bulanamayacağı" mütalaa edilmiştir. ${ }^{[1]}$

Taksirle yaralama suçlamasıyla hazırlanan iddianame ile açılan ceza davası, hekim ve diğer personeller açısından "beraat kararı" ile sonuçlandırılmış, kararın gerekçesine de Adli Tıp Kurumu raporunun içeriği alınmıştır. ${ }^{[1]}$

Ceza Mahkemesi kararı, katılan (hasta) tarafından temyiz edilmiş ve Yargıtay'da incelenen dosyada, ilk derece mahkemesinin kararının ve gerekçesinin yeterli ve şüpheden uzak olduğu sonucuna varılmış, beraat kararı onanmış ve bu şekilde kesinleşmiştir. ${ }^{[1]}$

\section{ÖRNEK OLGU 2}

Diz protezinin enfekte olması sebebiyle operasyon planlanmış ve ameliyat sırasında spinal anestezi yapılmıştır. Yapılan spinal anestezi sonrasında hastada parapleji oluşmuş ve bir daha düzelmemiş, sekel olarak kalmıştır. ${ }^{[2]}$

Hasta, ortopedi ve travmatoloji uzmanı ile anestezi uzmanlarını ve adı geçen herkesi Cumhuriyet Başsavcılığı'na şikâyet etmiş, "kullanmakta olduğu kumadin (coumadin)'in ameliyattan 10 gün önce kesilmesi gerektiğinin kendisine söylenmediğini, ilacın ameliyattan dört gün öncesinde kesildiğini, bu sebeple belinde kanama olduğunu ve kanamaya bağlı olarak da felç olduğunu, taksirle yaralama suçunun unsurlarının oluştuğunu" iddia etmiştir. ${ }^{[2]}$

Cumhuriyet Başsavcılığınca Haziran 2016'da “kovuşturmaya yer olmadığı kararı" verilmiş, itiraz üzerine inceleme yapan Sulh Ceza Mahkemesi, Ağustos 2016'da itirazı reddetmiştir. Adalet Bakanlığının talebi üzerine dosya, incelenmek üzere Yargıtay'a intikal ettirilmiş, Yargıtay da, "şikâyetçinin, coumadin isimli ilacın 10 gün yerine dört gün önce kesildiği iddiasının doğruluğunun ve yerindeliğinin araştırılması gerektiği, konu araştırılmaksızın başvurunun reddedilmesinin adalete erişimi engellediği” gerekçesiyle Sulh Ceza Mahkemesinin kararını kaldırmış ve bu şekilde ceza yargılamasının yolu açılmıştır. ${ }^{[2]}$

\section{ÖRNEK OLGU 3}

Davacı kurum, diz protezi ameliyatı sırasında kullanılan çimentonun gereksiz yere kullanıldığını iddia etmiş ve bedelinin tedarikçi firmadan rücuen tahsilini talep etmiştir. ${ }^{[3]}$

Yapılan değerlendirmede mahkeme, tedarikçi firmanın anılan malzemeyi usulüne uygun tedarik ettiğine, siparişe uygun malzeme getirdiğine, malzemenin gerekip gerekmediği ve ne şekilde kullanılacağı konusunda firmanın söz sahibi olmadığına, bu konudaki kararın malzemeyi kullanan hekimde olduğuna karar vermiş ve davayı reddetmiştir. ${ }^{[3]}$

Davacı kurum davanın temyizen incelenmesini talep etmiş, Yargıtay da yaptığı değerlendirmede, "davacı kurumun, iddialarını destekler tarzda kanitlar ortaya koyamamış olması sebebiyle" ilk derece mahkemesi kararını onamıştır. ${ }^{[3]}$

\section{ÖRNEK OLGU 4}

Kasım 2012'de iki taraflı (bilateral) diz artroplastisi uygulanan hasta, taburcu edildikten dört gün sonra evinde ölmüş, Adli Tıp Kurumu'nca yapılan otopsi ile ölüm sebebinin "kalp damar hastalığı" olduğu raporlanmıştır. ${ }^{[4]}$

Ölenin mirasçıları doktorların kusurlarının ölüme sebep olduğu iddiası ile Cumhuriyet Başsavcılığı'na müracaat etmiş, yapılan soruşturma sırasında, üniversite adli tıp kürsüsünden alınmış "hekimin kusurlu olduğuna dair rapor" da soruşturma dosyasına sunulmuş olmasına rağmen, Cumhuriyet Savcısı Adli Tıp Kurumu (ATK) raporu doğrultusunda "kovuşturmaya yer olmadığına dair karar" vermiştir. İtiraz incelemesi Ağır Ceza mahkemesinde yapılmış ve itirazın reddine karar verilmiştir. İtirazın reddine dair karar, kanun yararına bozma yoluyla Yargıtay'a gelmiş ve Yargıtay da "ATK raporunda ölümün sebebi belirtilmiş ancak hekimin kusuru olup olmadığı incelenmemiştir. Üniversiteden alınan rapor ile ATK raporu arasındaki çelişki giderilmemiştir. Ameliyat öncesi tetkiklerde kalp gölgesinin artmış olduğuna dair radyoloji raporu olduğu, bu durumda, ameliyat öncesi dönemde kardiyoloji konsültasyonu yapılarak iki taraflı diz protezi ameliyatını tolere edip edemeyeceğinin sorulup sorulmadı̆̆ııın mahkemece araştırılması gerekirken, Cumhuriyet Savcılı̆ğ'nın kararına karşı itirazın reddedilmesi bozmayı gerektirmiştir" kararı ile ceza yargılamasının yolunu açmıştır. ${ }^{[4]}$

\section{ÖRNEK OLGU 5}

Tibial kondillerde (platolarda) yaklaşık $3 \mathrm{~cm}$ defektli gonartroz olgusuna revizyon diz artroplastisi yapılmış, 
Sosyal Güvenlik Kurumuna (SGK) fatura edilmiştir. SGK'da yapılan geriye dönük inceleme sırasında " $3 \mathrm{~cm}$ defektin revizyon diz protezi ile doldurulamayacağı, revizyon malzemesi kullanılmasının Sağlık Uygulama Tebliği'ne uygun olmadığı" gerekçesi ile fatura tutarının beş katı para cezası mahsuplaşma yoluyla uygulanmıştır. ${ }^{[5]}$

Davacı hastane, SGK'nın örnekleme yoluyla yaptığı kesintiye itiraz etmiştir. ${ }^{[5]}$

Mahkeme, bilirkişiden gelen rapor doğrultusunda "davanın kabulüne, para cezasının iptaline" karar vermiş, Yargıtay da ilk derece mahkemesi kararını onamıştır. ${ }^{[5]}$

\section{ÖRNEK OLGU 6}

Iddiaya göre, davacıya Aralık 2010'da diz protezi yapılmış, 11 gün sonra taburcu edilmiş ve takiplerinde de fizik tedaviye devam edilmiştir. Ağrıları geçmeyen hasta başka bir hastaneye müracaat etmiş, ağrılarının, daha önce konulmuş olan protezlerin büyük olması sebebiyle devam ettiği söylenmiş ve ikinci ameliyat yapılmıştır. Daha sonrasında dizde yapışıklık gelişmiş ve üçüncü ameliyat yapılmıştır. Davacı, ilk ameliyatı yapan hekime ve hastaneye yönelik olarak açtığı dava ile maddi ve manevi zararlarının tazmini talep etmiştir. ${ }^{[6]}$

Adli Tıp Kurumu (ATK), hekimin kusurunun olmadığı yönünde rapor tanzim etmiş, davacı rapora itiraz etmiştir. Mahkeme itirazları dikkate almamış ve ATK raporu doğrultusunda hüküm kurmuş, davayı reddetmiştir. ${ }^{[6]}$

Dava, davacı tarafından temyiz edilmiş ve Yargıtay, incelemesi sonrasında, "Davacı, alınan rapora itiraz etmiş, mahkemeden konu ile ilgili yeniden bir rapor alınmasını istemiş, davacı tarafin bu talebi karşılanmadan yetersiz bilirkişi raporu ile hüküm tesis edilmiştir. O halde mahkemece, davacının davalı hastanede olduğu ameliyat ve ameliyat sonrası devam eden fizik tedavi nedeniyle doktor hatasının bulunup bulunmadığı, söz konusu ameliyat nedeniyle ikinci ve üçüncü ameliyatı olmak zorunda kalıp kalmadığı, davacının iddiaları ve özellikle davacının bilirkişi raporlarına yaptığı itirazları da değerlendirilip tartışılmak üzere üniversite öğretim üyelerinden oluşturulacak, konusunda uzman akademik kariyere sahip yeni bir bilirkişi kurulundan nedenlerini açıklayıcı, taraf, mahkeme ve Yargıtay denetimine elverişli bir rapor alınmak suretiyle hasıl olacak sonuca uygun bir karar verilmesi gerekirken, eksik inceleme ile hüküm tesisi usul ve yasaya aykırı olup, bozmayı gerektirir." gerekçesiyle ilk derece mahkemesinin kararını bozmuş ve yeniden incelenmek üzere geri göndermiştir. ${ }^{[6]}$

\section{TARTIŞMA}

- Yargıtay kararlarında sıklıkla rastladığımız; "Mahkemece yapılacak iş, üniversitelerin ana bilim dallarından seçilecek akademik kariyeri olan uzmanlardan oluşacak üç kişilik bilirkişi kuruluna dosya tevdi edilerek, davalıların açıklanan hukuki konum ve sorumlulukları, dosyada mevcut delillerle ve raporlarla birlikte bir bütün olarak değerlendirilip, yapılması gerekenle yapılan müdahale ve tedavinin ne olduğunu, tıbbın gerek ve kurallarına göre olayda davalıların sorumluluğunu gerektirecek ihmal ve hata bulunup bulunmadığını gösteren, nedenlerini açıklayıcı, taraf, mahkeme ve Yargıtay denetimine elverişli rapor alınmak suretiyle hasıl olacak sonuca uygun bir karar vermekten ibarettir. Mahkemece, değinilen bu yön göz ardı edilerek eksik araştırma ile yazılı şekilde hüküm kurulmuş olması usul ve yasaya aykırıdır” kalıbı, kısmen katıldığımız, kısmen de eleştirdiğimiz bir husustur. Şöyle ki, hâkimin görevi olayı aydınlatmaktır. Olayı, zararı, hekimin davranışını, davranışın standartlara uygun olup olmadığını, oluşan zarar ile hekimin davranışı arasında sebep-sonuç ilişkisi (nedensellik bağı) olup olmadığını araştırmak davanın aydınlatılması anlamına gelecek olup bu hususta hâkimin dayanağı, bilirkişi görüşleridir. Yargıtay'ın bu husustaki görüşü yerindedir, katıldığımız taraftır.

Bilirkişilik müessesesi, usul kuralları ile düzenlenmiş bir hukuki müessesedir. Gerek Hukuk Muhakemeleri Kanunu, gerekse de Ceza Muhakemeleri Kanunu ve hatta Idari Yargılama Usul Kanununda bilirkişiye başvurmanın usul ve esasları belirlenmiştir.

Hâkime, bilirkişi görüşü için "üniversitelere başvurması gerekir" gibi bir yönlendirme, Bilirkişilik Kanunu ile, uygulama yönetmeliği ile ve en önemlisi de saha gerçekleri ile örtüşmemektedir. Diğer yandan, hâkime yönlendirme yapılmasının, Anayasanın 138. Maddesinin ${ }^{[7]}$ ihlali anlamına geleceği, "Hâkimler görevlerinde bağımsızdırlar; Anayasaya, kanuna ve hukuka uygun olarak vicdanî kanaatlerine göre hüküm verirler. Hiçbir organ, makam, merci veya kişi, yargı yetkisinin kullanılmasında mahkemelere ve hâkimlere emir ve talimat veremez; genelge gönderemez, tavsiye ve telkinde bulunamaz" ilkelerine aykırı olacağı ve bu şekilde adil yargılanma hakkının ihlal edildiğine dair bir Anayasa Kararı da mevcuttur. ${ }^{[8]}$

Sahaya uygunsuzluk anlamında bir diğer eleştirimiz de, üniversitelerin ilgili branş hekimlerine sorulması gerektiğine dair vurgunun her zaman beklenen sonucu karşılamadığını defalarca 
görmüş olmamızdan kaynaklanmaktadır. Bilirkişilik yapmak için öncelikle hukukun temel kurallarını bilmek, kamu hukuku ile özel hukuk ayırımını ve uygulamalarını bilmek, sözgelimi taleple bağlılık ilkesini, kusur, sorumluluk, illiyet bağı gibi hukuki nitelendirmeleri bilmek ve bu bilgiyi rapora yansıtmak gerekmektedir. Ortopedi ve travmatoloji biliminin standartlarına üniversite öğretim üyelerinin hâkim olduğu noktasında duraksama yoktur ancak bir yandan bilirkişi olabilmek için temel hukuk kurallarını içeren bilirkişilik eğitim sertifikası şartı aranırken diğer yandan bu sertifika sorgulanmaksızın dosyanın üniversiteye gönderilmesi, hele de heyete bir adli tıp uzmanı katılmamışsa, bilirkişi raporunun sadece tıbbi değerlendirmeler içermesi, hukuka hizmet edecek önemli noktalara raporda yer verilmemesi sonucuna yol açabilmektedir.

- Enfeksiyon sebebiyle ameliyattan dört ay sonra revizyon gereken ilk örnek olguda Adli Tıp Kurumu (ATK) raporu yeterli görülmüş, iki kez revizyon gereken altıncı örnekteki olguda ise sadece ATK'dan rapor alınmış olması, itirazın değerlendirilmemiş olması, başka bir kurumdan görüş alınmamış olması eksik inceleme sebebi olarak değerlendirilmiştir.

Yargıtay'ın tutarsızlığı olarak nitelendirilebilecek bu durum birçok olguda sıklıkla karşılaştığımız bir durum olup, Yargıtay'ın belirli bir prosedür izlemediği, farklı dairelerden farklı yaklaşımlar çıkabileceği gibi, aynı daire içerisinden dahi farklı kararlar çıkabileceği, uygulama birliği olmadığının bilinmesi, önem arz etmektedir.

- Bilinmesi gereken bir diğer husus da bilirkişi raporlarının takdiri delil olduğu ve hâkimi bağlamayacağıdır. Hukuk sistemimizde deliller kesin delil ve takdiri deliller olmak üzere ikiye ayrılmakta olup kesin deliller üzerinde hâkimin takdir yetkisi yoktur.

Uygulamada sıklıkla gördüğümüz ve eleştirdiğimiz bir diğer husus, bölge bilirkişi listesine kayıtlı bilirkişiler ile üniversite öğretim üyelerinin, TÜBITAK gibi bilimsel kuruluşlarla TOTBID gibi meslek örgütlerinin, Adli Tıp Kurumu görüşleri ile herhangi bir uzman görüşünün, taraflarca talep edilmiş ve temin edilmiş uzman mütalaasının delil değerinin aynı olduğunun hâkimlerce göz ardı edilmesi, "Adli Tıp Kurumu resmi bilirkişidir" gibi mesnetsiz bir gerekçe ile diğer bilirkişi raporlarının görmezden gelinmesi hususudur.

Yargıtay'ın bu hususa yaklaşımının da bir çizgi takip etmiyor olması, sunduğumuz birinci olgudaki
Yargıtay 12. Ceza Dairesinin ${ }^{1}$, altıncı olgudaki Yargıtay 13 . Hukuk Dairesi[6] ile tam zıt yaklaşımlar sergilemiş olması karşısında sorunun çözümünün yakın olduğunu söyleyebilmek pek mümkün görünmemektedir.

- Kumadin (Coumadin) kullanım öyküsü ve felç içerikli ikinci örnek olgu ile ameliyat öncesi (preoperatif) kardiyoloji konsültasyonu içerikli dördüncü örnek olguda işletilen yol, "Kanun Yararına Bozma" yolu olup, Ceza Muhakemesi Kanunu'nun (CMK) 309-310. maddeleri ile istisnai bir yol olarak karşımıza çıkmaktadır. ${ }^{[9]}$

Hâkim veya mahkeme tarafindan verilen ve istinaf veya temyiz yolunun kapalı olması sebebiyle kesinleşen kararların, (Cumhuriyet Başsavcısı'nın, temyiz yolu açık olup da temyiz edilmemiş kararlar için de talep hakkı vardır) Adalet Bakanı istemiyle Yargıtay tarafından tekrar değerlendirilmesi olarak tanımlanabilecek bu yol, olağan bir kanun yolu değildir. Dosya, ancak, ilgililerin Adalet Bakanlığı'ndan talebi ve sonrasında Adalet Bakanı'nın verebileceği emir ile Yargıtay'a tevdi edilebilecektir.

İstinaf veya temyiz edilmeden kesinleşen birtakım kararlara karşı olağanüstü kanun yollarının açık olması, dosyanın, özellikle ceza soruşturmaları ve yargılama sonrasında verilen "hükmün açıklanmasının geri bırakılması kararları"nın sonrasında da takip edilmesi, olası hak kayıpları yönünden önem kazanmaktadır.

- Gereksiz malzeme kullanımına örnek teşkil edecek üçüncü örnek olgudan anlaşılması ve genel olarak da bilinmesi gereken husus şudur:

Malzemenin kullanımı elbette hekimin inisiyatifindedir ancak hekim bu konuda mesleki standartlarla, başka bir ifadeyle, bilirkişi görüşleri ile sınırlandırılmış durumdadır. Malzeme kullanımında genel ölçüt, özel durumları ayrık tutmak şartıyla, ortopedi ve travmatoloji uzmanı bilirkişilerin kolaylıkla "uygundur" diyebileceği malzemelerin kullanılmasıdır. Bilirkişilerin bu görüşleri, ortopedi ve travmatoloji alanındaki standartların belirlenmesinde mahkeme için bir gösterge olacaktır.

Bilirkişilerin bilmediği, kullanmadığı, tasvip etmediği malzemelerin de hukuka uygun, hastanın tıbbi durumuna ve endikasyona uygun olmak şartıyla kullanılması yönünde bir engel yoktur. Bu gibi durumlarda hekime düşen görev, genellikle kullanılan malzemenin niçin kullanılmadığının, kullanılan malzemenin ne amaçla tercih edildiğinin, bilimsel, sosyal, ekonomik veya diğer sebeplerin dosyaya doğru ve net şekilde yansıtılmasıdır. 
- Ameliyat öncesi hazırık dönemi öncelikle branş hekiminin sorumluluğunda olup, hastanın anestezi uzmanı tarafindan ameliyata kabul edilmiş olması, ameliyat öncesi hazırlıkların tam ve eksiksiz yapıldığının mutlak kanıtı değildir.

Ameliyat öncesi dönem hazırlıkları genellikle hastayı anesteziye sunma amaçlı olup, ameliyat sonrası dönemde oluşabilecek riskleri de ortaya koyabilecek şekilde bir ameliyat hazırlığı, tıbbi ve hukuki riskleri azaltmak adına özel önem gösterilmesi gereken bir husustur.

- Hekim, Sağlık Uygulama Tebliğini, en azından kendi uygulama alanı ile ilgili temel özellikleri bilmek zorundadır. ${ }^{[10,11]}$ Sağlık Uygulama Tebliği hükümlerine uymayacak malzemelerin kullanılması, işlemlerin yapılması elbette mümkündür fakat olası yaptırımları, uyuşmazlıkları önlemek adına, aykırılığın gerekçesi, proaktif olarak, işlem yapılmadan, malzeme kullanılmadan önce hastane yönetimine, idareye bildirilmeli, gerekli tutanak ve dayanaklar dosyaya kaydedilmeli, izin alınmalıdır. İznin alınamadığı durumlarda, idare ya da yönetim alternatif bir çözüm yolu bulmak zorundadır ve her somut olay için farklı yollar bulabilmek de mümkündür. Hekime düşen görev, endikasyon ve malzeme seçimleri konusunda hasta yararı ve kamu yararı arasında bir denge kurmak ve bu dengenin tüm unsurlarını hastane yönetimi ile paylaşmak, kararı yönetime bırakmaktır.

\section{KAYNAKLAR}

1. Yargitay 12. Ceza Dairesi E. 2019/10127 K. 2020/4991 T. 12.10.2020. https://karararama.yargitay.gov.tr/ YargitayBilgiBankasilstemciWeb/

2. Yargıtay 12. Ceza Dairesi, E. 2017/1239, K. 2017/5807 T. 4.7.2017. https://karararama.yargitay.gov.tr/ YargitayBilgiBankasilstemciWeb/

3. Yargıtay 13. Hukuk Dairesi, E. 2011/3213, K. 2011/11130, T. 6.7.2011. https://karararama.yargitay.gov.tr/ YargitayBilgiBankasilstemciWeb/

4. Yargitay 12. Ceza Dairesi, E. 2014/12660, K. 2014/20855, T. 24.10.2014. https://karararama.yargitay.gov.tr/ YargitayBilgiBankasilstemciWeb/

5. Yargıtay 3. Hukuk Dairesi, E. 2020/944, K. 2020/4710, T. 24.9.2020. https://karararama.yargitay.gov.tr/ YargitayBilgiBankasilstemciWeb/

6. Yargıtay 13. Hukuk Dairesi, E. 2016/26899, K. 2019/12164, T. 5.12.2019. https://karararama.yargitay.gov.tr/ YargitayBilgiBankasilstemciWeb/

7. Türkiye Cumhuriyeti Anayasası. Kanun No: 2709, Kabul Tarihi: 7.11.1982. https://www.tbmm.gov.tr/anayasa/ anayasa_2018.pdf

8. Anayasa Mahkemesinin 03/06/2010 tarih, 2009/69 E, 2010/79 sayılı kararı, 22/10/2010 tarihli Resmî Gazete.

9. Ceza Muhakemesi Kanunu. Kanun Numarası: 5271 Kabul Tarihi: 4/12/2004 Yayımlandığı Resmî Gazete: Tarih: 17/12/2004, Sayı: 25673. https://www.mevzuat.gov.tr/ MevzuatMetin/1.5.5271.pdf

10. Sosyal Güvenlik Kurumu Sağlık Uygulama Tebliği. https:// www.resmigazete.gov.tr/eskiler/2013/03/20130324-3.pdf

11. Sosyal Güvenlik Kurumu Sağlık Uygulama Tebliğinde Değişiklik Yapılmasına Dair Tebliğ. https://www.resmigazete. gov.tr/eskiler/2021/04/20210428M1-1.htm 